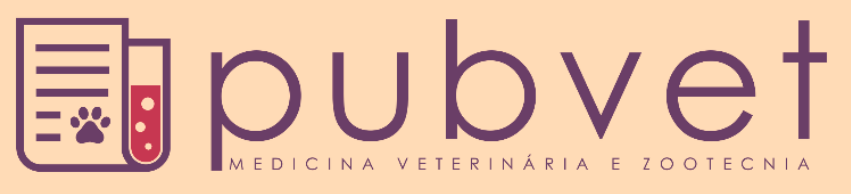

https://doi.org/10.31533/pubvet.v14n4a559.1-5

\title{
Ocorrência de Dioctophyma renale em cão proveniente do município de Valença-RJ: relato de caso
}

\author{
Luana Moura Silva Bastos*0 \\ *Pós-graduanda pelo Centro de Ensino Superior de Valença, Valença-RJ, Brasil. E-mail: luanavet89@gmail.com
}

Resumo. O Dioctophyma renale é um parasita que acomete o rim de cães e outras espécies, sendo a infecção adquirida pela ingestão de larvas que podem estar presentes em peixes, rãs ou anelídeos aquáticos. Esse parasita normalmente é encontrado no rim direito, podendo ser observado também em rim esquerdo, cavidade abdominal, tecido subcutâneo, bexiga e raramente nos testículos. A infecção geralmente apresenta-se assintomática, podendo ocorrer sinais clínicos como inapetência, disúria e cólica renal. O diagnóstico é feito através da presença de ovos do parasita na urina, exames de imagem, e na maioria dos casos realizado pela necropsia, ou achados durante procedimentos cirúrgicos. $\mathrm{O}$ tratamento recomendado é a remoção cirúrgica do nematódeo, em casos diagnosticados precocemente, e em casos tardios, a nefrectomia do rim afetado. O presente trabalho teve como objetivo relatar um caso de dioctofimose em um cão no Município de Valença, RJ, onde foi realizada a nefrectomia do rim afetado, após ter sido diagnosticado a parasitose através de exame ultrassonográfico.

Palavras chave: nefrectomia, parasita, rim

\section{Occurrence of Dioctophyma renale in a dog from Valença-RJ: case report}

Abstract. Dioctophyma renale is a parasite that affects the kidney of dogs and other species. The infection is acquired by ingestion of larvae that may be present in fish, frogs or aquatic annelids. This parasite is usually found in the right kidney and can also be seen in the left kidney, abdominal cavity, subcutaneous tissue, bladder and rarely in the testicles. The infection is usually asymptomatic and clinical signs such as inappetence, dysuria and renal colic may occur. Diagnosis is made by the presence of parasite eggs in the urine, imaging tests, and in most cases performed by necropsy, or findings during surgical procedures. The recommended treatment is surgical removal of the nematode, in early diagnosed cases, and in late cases, nephrectomy of the affected kidney. This study aimed to report a case of dioctophimosis in a dog in the city of Valença, RJ, where nephrectomy of the affected kidney was performed after parasitosis was diagnosed by ultrasound examination.

Keywords: nephrectomy, parasite, kidney

\section{Ocurrencia de Dioctophyma renale en un perro de Valença-RJ: reporte de un caso clínico}

Resumen. Dioctophyma renale es un parásito que afecta el riñón de los perros y otras especies. La infección se adquiere por la ingestión de larvas que pueden estar presentes en peces, ranas o anélidos acuáticos. Este parásito generalmente se encuentra en el riñón derecho y también se puede ver en el riñón izquierdo, la cavidad abdominal, el tejido subcutáneo, la vejiga y rara vez en los testículos. La infección suele ser asintomática y 
pueden aparecer signos clínicos como inapetencia, disuria y cólico renal. El diagnóstico se realiza por la presencia de huevos de parásitos en la orina, exámenes de imágenes y, en la mayoría de los casos, realizadas por necropsia o hallazgos durante los procedimientos quirúrgicos. El tratamiento recomendado es la extirpación quirúrgica del nematodo, en los casos de diagnóstico temprano y, en los casos tardíos, la nefrectomía del riñón afectado. Este estudio tuvo como objetivo informar un caso de dioctofimosis en un perro en la ciudad de Valença, RJ, donde se realizó la nefrectomía del riñón afectado después de que se diagnosticara parasitosis mediante examen de ultrasonido.

Palabras clave: nefrectomía, parásito, riñón

\section{Introdução}

O Dioctophyma renale é conhecido como o maior nematódeo que acomete os animais domésticos, localizando-se preferencialmente no parênquima renal e cavidade abdominal (Monteiro et al., 2002; Urquhart, 1996). Os cães se infectam ao ingerir anelídeos, sapos, peixes ou rãs parasitados com a forma larval (Varzone et al., 2008). Os vermes se reproduzem nos rins desses hospedeiros e eliminam os ovos na urina (Kommers et al., 1999; Pedrassani \& Nascimento, 2015).

Os animais mais acometidos são cães errantes e com hábitos alimentares pouco seletivos, como os cães que se alimentam de peixes ou crustáceos. Os sinais clínicos mais comuns são inapetência, anorexia e emagrecimento, sendo a maioria dos casos assintomáticos. Essas alterações variam de acordo com a localização do parasita, grau de desenvolvimento e espécie acometida (Colpo et al., 2007).

O diagnóstico é realizado pela presença de ovos na urina, radiografia e ultrassonografia. Mas como a incidência de dioctofimose sintomática é baixa, na maioria das vezes o diagnóstico é realizado somente na necropsia (Kommers et al., 1999). Não existe tratamento clínico efetivo (Forrester \& Lees, 1998), sendo o tratamento indicado a nefrectomia ou a nefrotomia, de acordo com a gravidade da lesão renal e da presença do parasita em um ou ambos os rins, entretanto é sempre preconizada a remoção do rim acometido (Slatter, 1998).

O objetivo deste trabalho é relatar a infecção por Dioctophyma renale em um cão no município de Valença.

\section{Relato de caso}

Um cão macho, sem raça definida, errante e de aproximadamente oito meses de idade, foi levado a Clínica Veterinária Chacrinha, com sinais de anorexia, êmese, emagrecimento e inapetência. Foi realizado exame físico do animal, onde não foi observada nenhuma alteração, sendo então, solicitados exames laboratoriais (hemograma e bioquímica renal). No hemograma o animal apresentou discreta anemia, leucocitose, eosinofilia, neutrofilia e linfocitose. Enquanto no exame bioquímico constatou elevação nos níveis séricos de ureia e creatinina.

O animal foi encaminhado para o setor de imagem, onde foi realizada ultrassonografia, para avaliação renal. De acordo com o exame foi possível visualizar aumento do rim esquerdo, com arquitetura interna modificada, contendo várias estruturas tubulares arredondadas com camada externa hiperecogênica e sua parte interna anecóica (Figura 1). Sendo esta imagem sugestiva do parasita Dioctophyma renale. A partir da confirmação do diagnóstico e localização do parasita, o animal foi encaminhado para cirurgia de nefrectomia do rim afetado.

Foi realizada incisão para acesso a cavidade abdominal, em seguida pode-se visualizar vários parasitas livres na cavidade (Figura 2). Posteriormente foi feita a nefrectomia do rim esquerdo, seguido da inspeção dos demais órgãos. O rim removido foi avaliado, sendo encontrados dois nematoides adultos e completa perda da arquitetura renal e espessamento da cápsula (Figura 3).

Após o tratamento cirúrgico o animal foi medicado e monitorado durante o pós -operatório, onde apresentou satisfatória recuperação, tanto clínica quanto laboratorial, recebendo alta oito dias após a cirurgia. 


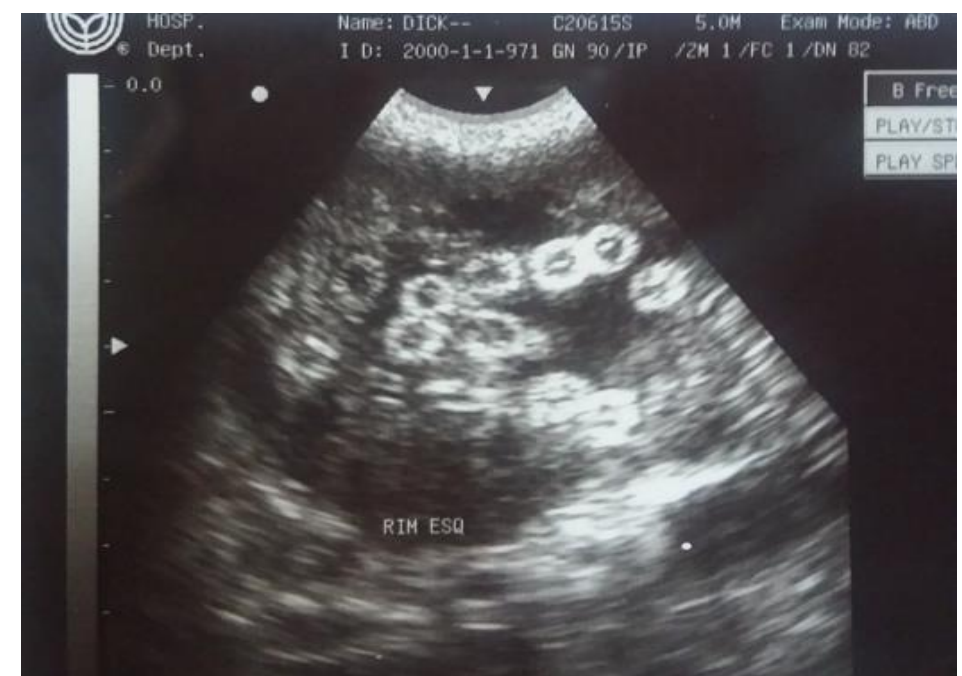

Figura 1. Imagem ultrassonográfica do rim esquerdo parasitado por D. renale.

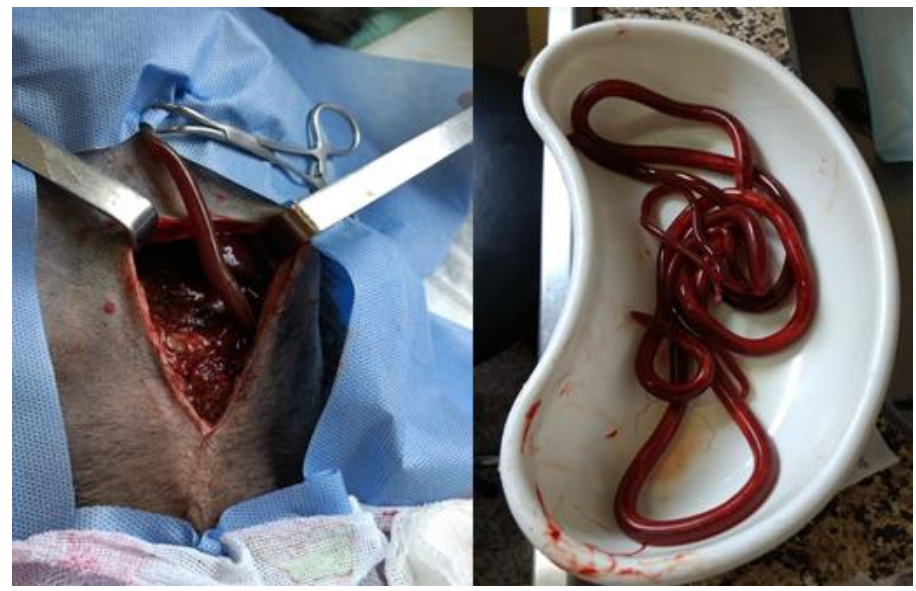

Figura 2. Parasita Dioctophyma renale.

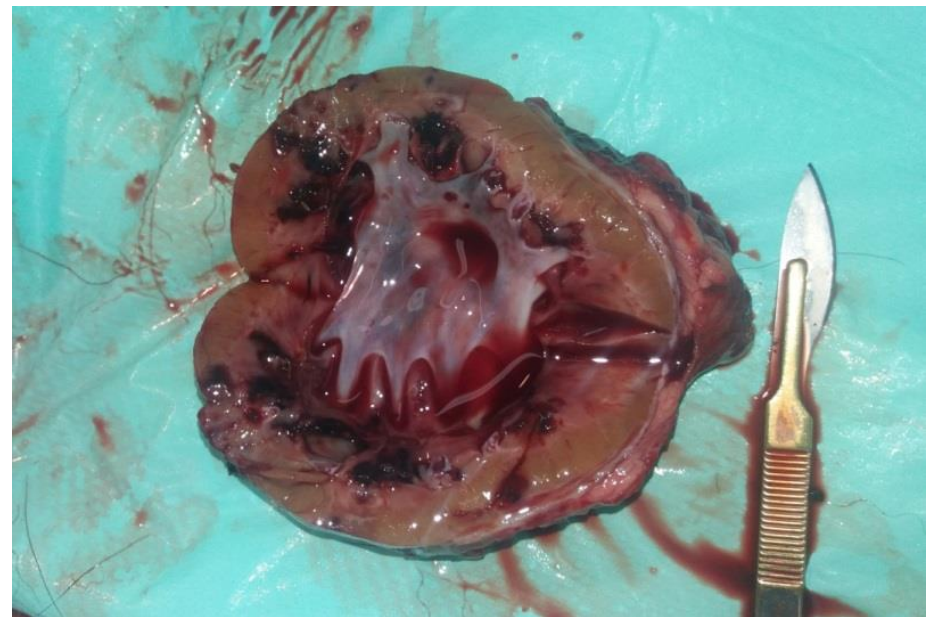

Figura 3. Rim esquerdo com perda de arquitetura e espessamento da cápsula.

\section{Discussão}

De acordo com as literaturas consultadas, o principal diagnóstico é pela identificação dos ovos do parasita na urina, além da necropsia (Ferreira Neto et al., 1971; Fortes, 2004; Leite et al., 2005), mas o animal deste relato foi encaminhado primeiramente para ultrassonografia abdominal, que foi suficiente para estabelecer o diagnóstico de Dioctophyma renale concordando com Alves et al. (2003). No hemograma do animal deste relato foi observada leucocitose por eosinofilia, concordando com os achados hematológicos descritos por (Birchard \& Sherding, 2008). Segundo Kommers et al. (1999) normalmente apenas o rim direito é 
acometido, provavelmente por sua proximidade com o duodeno, sendo este fato não confirmado no presente estudo, pois o rim esquerdo que se encontrava parasitado.

Esse parasita provoca alterações renais bem características, como inflamação e destruição completa do parênquima renal, transformando o rim em uma cápsula fibrosa (Ferreira et al., 2010). O parasita destruiu por completo o parênquima renal do paciente e a cápsula estava extremamente espessada e irregular, como relatado anteriormente por Leite et al. (2005).

O tratamento efetivo consiste na remoção do Dioctophyma cirurgicamente ou do rim afetado, método conhecido como nefrectomia, sendo realizado igualmente com o animal do presente estudo. (Alves et al., 2003). Em contrapartida a recuperação vai depender dos órgãos acometidos e do grau de destruição causado pelo parasita (Kano et al., 2003). Neste relato o cão tinha apenas um rim acometido, tendo uma boa recuperação.

$\mathrm{O}$ animal deste relato foi resgatado na rua, sendo assim apresentava hábito alimentar pouco seletivo, $\mathrm{o}$ que confirma as observações de Kommers et al. (1999), Mayrink et al (2000), Colpo et al. (2007) e Cottar et al. (2012) que descreveram que animais com dioctofimose geralmente são animais de rua.

\section{Conclusão}

A infecção por Dioctopyma renale frequentemente é assintomática, o que torna fundamental, uma boa abordagem diagnóstica para o sucesso no tratamento, incluindo como diagnóstico diferencial em casos que os animais apresentem leucocitose por eosinofilia. O exame ultrassonogáfico é uma técnica complementar indispensável para o diagnóstico da doença, identificação do rim acometido, verificação do rim contralateral e avaliação dos demais órgãos, assim, oferece informações relevantes para o tratamento adequado.

\section{Referências bibliográficas}

Alves, L. C., Teixeira, M. A. da C., Queirolo, M. T. C., Witz, M. I., Jesus, J. R., Porto, C. G., \& MARQUES, R. (2003). Diagnóstico por ultra-som de dioctophyma renale em cães. Veterinária Em Foco, 1(1), 35-41.

Birchard, S. J., \& Sherding, R. G. (2008). Manual Saunders: clínica de pequenos animais. In Ed. Roca (Vol. 3).

Colpo, C. B., Silva, A. S. S., Monteiro, S. G., Stainki, D. R., Camargo, D. G., \& Colpo, E. T. B. (2007). Ocorrência de Dioctophyma renale em cães no município de Uruguaiana-RS. Revista Da FZVA, 14(2), 175-180.

Cottar, B. H., Dittrich, G., Ferreira, A. A., Carvalho, A. C. P., Albernaz, V. G. P., Luz, M. T., \& Tasqueti, U. I. (2012). Achados ultrassonográficos de cães parasitados por Dioctophyma renale-estudo retrospectivo. Veterinária e Zootecnia, 19(1-S. 1), 8-11.

Ferreira Neto, J. M., Nunes, L. P., Bernis, W. O., \& Pippi, N. (1971). Observações clínicas da dioctofimose em um cão e transplantação do parasito. Arquivos Da Escola de Veterinaria Da Universidade Federal de Minas Gerais, 23, 29-35.

Forrester, S. D., \& Lees, G. E. (1998). Nefropatias e ureteropatias. In S. J. Birchard \& R. G. Sherding (Eds.), Manual Saunders Clínica de Pequenos Animais (pp. 901-925). Roca.

Fortes, E. (2004). Parasitologia veterinária (4th ed.). Editora ícone.

Kano, F. S., Shimada, M. T., Suzuki, S. N., Osaki, S. C., Menarim, B. C., Ruthes, F. R. V., \& Laidane Filho, M. A. (2003). Ocorrência da dioctofimose em dois cães no município de Guarapuava-PR. Semina: Ciências Agrárias, 24(1), 177-180.

Kommers, G. D., Ilha, M. R. S., \& Barros, C. S. L. (1999). Dioctofimose em cães: 16 casos. Ciência Rural, 29(3), 517-522.

Leite, L. C., Círio, S. M., Diniz, J. M. F., Luz, E., Navarro-Silva, M. A., Silva, A. W. C., Leite, S. C., Zadorosnei, A. C., Musiat, K. C., \& Veronesi, E. M. (2005). Lesões anatomopatológicas presentes na infecção por Dioctophyma renale (Goeze, 1782) em cães domésticos (Canis familiaris, Linnaeus, 1758). Archives of Veterinary Science, 10(1), 95-101. 
Mayrink, K. C., Paes-de-Almeida, E. C., \& Thomé, S. M. G. (2000). Dioctophyma renale (Goeze, 1782) em cães. Caderno Técnico Científico Da Escola de Medicina Veterinária Da Universidade Do Grande Rio, 2, 20-40.

Monteiro, S. G., Sallis, E. S. V., \& Stainki, D. R. (2002). Infecção natural por trinta e quatro helmintos da espécie Dioctophyma renale (Goeze, 1782) em um cão. Revista Da FZVA, 9(1), 9.

Pedrassani, D., \& Nascimento, A. A. (2015). Verme gigante renal. Revista Portuguesa de Ciências Veterinárias, 110(593-594), 30-37.

Slatter, D. H. (1998). Manual de cirurgia de pequenos animais (Vol. 2). Manole São Paulo.

Urquhart, G. M. (1996). Parasitologia veterinária (2nd ed.). Guanabara Koogan.

Varzone, J. R. M., Aquino, L. P. C. T., \& Rodovalho, M. V. T. (2008). Achados macroscópicos de lesões resultantes do parasitismo por Dioctophyma renale em lobo-guará (Chrysocyon brachyurus)relato de caso. Ensaios e Ciência: Ciências Biológicas, Agrárias e da Saúde, 12(2), 171-178.

Recebido: 17 de novembro, 2019.

Aprovado: 16 de dezembro, 2019.

Publicado: 26 maio 2020.

Licenciamento: Este artigo é publicado na modalidade Acesso Aberto sob a licença Creative Commons Atribuição 4.0 (CC-BY 4.0), a qual permite uso irrestrito, distribuição, reprodução em qualquer meio, desde que o autor e a fonte sejam devidamente creditados. 